\title{
RESEARCH
}

Open Access

\section{Nutritional management of phenylalanine hydroxylase (PAH) deficiency in pediatric patients in Canada: a survey of dietitians' current practices}

Nataliya Yuskiv ${ }^{1 *}$, Beth K. Potter ${ }^{2}$, Sylvia Stockler ${ }^{1}$, Keiko Ueda ${ }^{3}$, Alette Giezen ${ }^{3}$, Barbara Cheng ${ }^{3}$, Erica Langley ${ }^{4}$, Suzanne Ratko ${ }^{5}$, Valerie Austin ${ }^{6}$, Maggie Chapman ${ }^{7}$, Pranesh Chakraborty ${ }^{4}$, Jean Paul Collet ${ }^{1}$, Amy Pender ${ }^{8}$ and In collaboration with the Canadian Inherited Metabolic Diseases Research Network (CIMDRN)

\begin{abstract}
Background: Phenylalanine hydroxylase (PAH) deficiency is one of 31 targeted inherited metabolic diseases (IMD) for the Canadian Inherited Metabolic Diseases Research Network (CIMDRN). Early diagnosis and initiation of treatment through newborn screening has gradually shifted treatment goals from the prevention of disabling complications to the optimization of long term outcomes. However, clinical evidence demonstrates that subtle suboptimal neurocognitive outcomes are present in the early and continuously diet-treated population with PAH deficiency. This may be attributed to variation in blood phenylalanine levels to outside treatment range and this, in turn, is possibly due to a combination of factors; disease severity, dietary noncompliance and differences in practice related to the management of PAH deficiency. One of CIMDRN's goals is to understand current practices in the diagnosis and management of PAH deficiency in the pediatric population, from the perspective of both health care providers and patients/families.
\end{abstract}

Objectives: We investigated Canadian metabolic dietitians' perspectives on the nutritional management of children with PAH deficiency, awareness of recently published North American treatment and nutritional guidelines in relation to PAH deficiency, and nutritional care practices within and outside these guidelines.

Methods: We invited 33 dietitians to participate in a survey, to ascertain their use of recently published guidelines and their practices in relation to the nutritional care of pediatric patients with PAH deficiency.

Results: We received 19 responses (59\% response rate). All participants reported awareness of published guidelines for managing PAH deficiency. To classify disease severity, $89 \%$ of dietitians reported using pre-treatment blood phenylalanine (Phe) levels, alone or in combination with other factors. 74\% of dietitians reported using blood Phe levels $\geq 360 \mu \mathrm{mol} / \mathrm{L}(6 \mathrm{mg} / \mathrm{dL})$ as the criterion for initiating a Phe-restricted diet. All respondents considered 120-360 $\mu \mathrm{mol} / \mathrm{L}$ (2-6 mg/dL) as the optimal treatment range for blood Phe in children 0-9years old, but there was less agreement on blood Phe targets for older children. Most dietitians reported similar approaches to diet assessment and counseling: monitoring growth trends, use of 3 day diet records for intake analysis, individualization of diet goals, counseling patients to count grams of dietary natural protein or milligrams of dietary Phe, and monitoring blood Phe, tyrosine and ferritin.

(Continued on next page)

\footnotetext{
* Correspondence: nyuskiv@cw.bc.ca

'University of British Columbia, Vancouver, British Columbia, Canada

Full list of author information is available at the end of the article
}

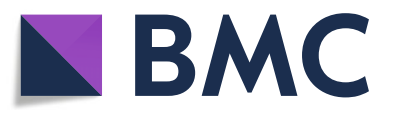

(c) The Author(s). 2019 Open Access This article is distributed under the terms of the Creative Commons Attribution 4.0 International License (http://creativecommons.org/licenses/by/4.0/), which permits unrestricted use, distribution, and reproduction in any medium, provided you give appropriate credit to the original author(s) and the source, provide a link to the Creative Commons license, and indicate if changes were made. The Creative Commons Public Domain Dedication waiver (http://creativecommons.org/publicdomain/zero/1.0/) applies to the data made available in this article, unless otherwise stated. 


\begin{abstract}
(Continued from previous page)
Conclusion: While Canadian dietitians' practices in managing pediatric PAH deficiency are generally aligned with those of the American College of Medical Genetics and Genomics (ACMG), and with the associated treatment and nutritional guidelines from Genetic Metabolic Dietitians International (GMDI), variation in many aspects of care reflects ongoing uncertainty and a need for robust evidence.
\end{abstract}

Keywords: PAH deficiency, Phenylketonuria, PKU, Management practices, Nutrition management, PAH deficiency practice guidelines, Metabolic dietitians' survey

\section{Background}

Phenylketonuria (PKU; OMIM 262600) is an autosomal recessive inborn error of phenylalanine metabolism caused by a deficiency of the phenylalanine hydroxylase (PAH) enzyme. PAH deficiency encompasses a spectrum of biochemical phenotypes from classic PKU (severe PAH deficiency) to mild hyperphenylalaninemia (with varying degrees of residual PAH activity). Untreated, PAH deficiency is characterized by elevated phenylalanine (Phe) levels in the blood and brain, resulting in neurological damage via impaired neurotransmitter metabolism and direct phenylalanine neurotoxicity [1]. Ground-breaking universal newborn screening for PAH deficiency, and treatment with a Phe-restricted diet and Phe-free or low Phe medical foods (formulas), have virtually eliminated severe $\mathrm{PAH}$ deficiency-related complications in early and continuously treated individuals in many populations throughout the world. This important achievement has shifted the goals of treatment from prevention of profound intellectual disability to optimization of health outcomes. Nutrition therapy, which aims at both maintaining blood Phe concentrations within treatment goals and meeting individual nutritional needs, remains a cornerstone of the management of PAH deficiency [1-4]. If administered appropriately and adhered to consistently, currently available treatment modalities are expected to result in health outcomes comparable with the general population. However, despite the medical and public health success story of the treatment of $\mathrm{PAH}$ deficiency, evidence suggests that long-term patient outcomes are not always optimal. Individuals living with PAH deficiency have higher risks of deficits in neurocognitive domains such as working memory, attention, processing speed and motor control, behavioural and psychosocial issues, growth and nutritional deficiencies, brain and bone pathology, and quality of life [5-8]. Delayed age at initiation of therapy, as well as variable lifelong blood Phe levels and nonadherence to treatment, have been identified as major contributors to the development of suboptimal outcomes [5, 9]. It has been argued that delivery of health care that is not aligned with established best practice, uncertainty in clinical decision making, and inconsistent access to care may also contribute to suboptimal outcomes for some patients $[7,10,11]$.
Relatively robust published evidence exists to support recommendations for many areas of management of PAH deficiency, such as diagnosis, treatment onset and duration, therapeutic goals, treatment targets and organization of care $[12,13]$. However, as with other rare diseases, high quality empirical evidence is not always available to support treatment decisions, resulting in several areas of uncertainty and inconsistencies in clinical decision-making that may ultimately lead to variability in health outcomes. For example, it is commonly agreed that life-long nutrition treatment should start as soon as possible for infants with initial untreated blood Phe levels $>600 \mu \mathrm{mol} / \mathrm{L}(10 \mathrm{mg} / \mathrm{dL})$ [3]. However, the evidence regarding the possible beneficial effect of a life-long Phe-restrictive diet in children whose initial untreated blood Phe levels are $360-600 \mu \mathrm{mol} / \mathrm{L}(6-10 \mathrm{mg} / \mathrm{dL})$ is sparse, leading to rather provisional recommendations for this patient subgroup [3,14]. Variability in the initiation of diet therapy, and other management practices related to PAH deficiency, have been reported both across countries and across centres within the same countries $[1,15]$. This may reflect in part the differences in treatment guidelines for PAH deficiency, developed by different groups and in different jurisdictions $[1,15]$.

The lack of uniformity in the management of PAH deficiency and new published evidence prompted the development of updated broad-based clinical guidelines (published by the American College of Medical Genetics and Genomics, ACMG) [3] and companion recommendations for the nutritional management of PAH deficiency (published by Genetic Metabolic Dietitians International, GMDI) [2], with the goal of improved patient care in North America. Both guidelines relied on independent evidence reviews conducted by experts from the National Institutes of Health and Agency for Healthcare Research and Quality [16, 17]. Both guidelines also integrated this evidence with a consensus of expert opinion in clinical practice areas for which evidence was lacking. For example, the development process for the nutritional management guidelines from GMDI included published evidence reviews, clinical protocols, consensus of experts via Delphi surveys and nominal group expert meetings, an external review, field 
testing, and revision, to reach at least $75 \%$ agreement [18]. The recent publication of these guidelines, coupled with previous research documenting variation in care, presented an opportunity to investigate how the guidelines are perceived by Canadian healthcare providers, and to identify important variations in care.

In this study, we aimed to ascertain Canadian metabolic dietitians' awareness of published guidelines for PAH deficiency and their approaches to nutritional management of PAH deficiency in the pediatric population. Identifying uncertainties in the nutritional management of pediatric PAH deficiency in Canada, from practitioners' perspectives, is important for understanding the impact and uptake of the new guidelines, identifying areas where knowledge translation and mobilization are needed, and prioritizing questions about treatment effectiveness for future research. This survey was distributed in 2016, and thus our primary comparison was with the recently published North American management guidelines for PAH deficiency [2, 3].

\section{Materials and methods Questionnaire}

Notwithstanding the challenges of management of adult phenylketonuria (PKU), especially of maternal PKU, we developed the survey with the pediatric population in mind. Many treatment concerns are different, and our focus on pediatric phenylalanine hydroxylase (PAH) deficiency is consistent with one of the goals of the Canadian Inherited Metabolic Diseases Research Network (CIMDRN); to understand current practices in the diagnosis and management of PAH deficiency in the pediatric population, from the perspective of both health care providers and patients/families.

The team of investigators included experienced registered metabolic dietitians from several Canadian metabolic centres, as well as a metabolic physician and investigators with expertise in survey research methods. We developed a study-specific questionnaire with 52 questions that covered self-reported awareness and use of the most recent published North American guidelines, personal and practice characteristics, and the following topics related to the nutritional management of PAH deficiency: classification of disease severity; frequency of monitoring and target ranges for surrogate biomarkers; recommended dietary intakes of key nutrients and methods recommended for patients to self-monitor intake of these nutrients; recommended use and accessibility of medical foods (formulas); use of vitamin/mineral supplements; frequency of clinic visits and communication with patients and their families; and methods of encouraging and monitoring patient adherence to therapy.

The survey questionnaire is available as a supplementary material.

\section{Sample selection and survey implementation}

Eligible participants were metabolic dietitians who provided care to children with PAH deficiency in Canada. Based on their clinic listing on the Genetic Metabolic Dietitians International (GMDI) website, we identified 33 Canadian metabolic dietitians in nine Canadian provinces and three territories. We could not be certain, based on the available information, that these dietitians specifically provided care to children with PAH deficiency; this eligibility criterion was thus incorporated into the questionnaire as a screening question.

Adapting Dillman's tailored design method [19], we made up to six contacts (between March and May 2016) to invite Canadian metabolic dietitians to participate in the survey. These included (a) a pre-notification email message sent out by one of the study investigators who is a metabolic dietitian; (b) an initial mailed invitation with a copy of the survey; (c) an initial email invitation with the link to the online survey; (d) a mailed reminder letter with a copy of the questionnaire, sent to non-respondents; (e) an email-reminder with the link; and (f) a final reminder email message, sent to remaining non-respondents.

Dietitians could respond to the survey by mail, using a prepaid return envelope that was included with each of the two questionnaires that were mailed; or online, through a REDCap platform, hosted on a secure BC Children's Research Institute server with participant access through a unique identification number and password.

In accordance with existing evidence regarding monetary incentives [20], we offered a \$25 iTunes gift card to each participant who completed the survey; and this was mentioned in the invitation letters and subsequent reminders.

\section{Analysis of survey data}

Data were entered into a REDCap database and exported to SAS 9.4 Software for descriptive analysis. We report proportions as all survey questions were categorical. Many questions used 4 or 5-point Likert-type scales and single-answer option; alternatively, some questions incorporated multiple answers which were expected to add up to more than $100 \%$. Where necessary and applicable, we grouped categories (e.g., "all" with "most", "excellent" with "good", "sometimes" with "rarely") to account for small numbers.

\section{Results}

Response rate and distribution of sample characteristics Of 33 Canadian metabolic dietitians invited to participate, we received twenty surveys of which nineteen had been completed. One respondent indicated on an initial screening question that he/she did not provide care for pediatric phenylketonuria (PKU), and therefore did not 
complete the full questionnaire (response rate, 19/32, $59 \%)$. Ten surveys (53\%) were submitted on paper and 9 (47\%) were completed online. We received responses from 14 centres, located in nine of the ten Canadian provinces. Of the 14 centres, 10 had only one respondent and a further 4 centres had multiple respondents. The majority of respondents had worked in metabolic nutrition services for more than 6 years $(74 \%)$, were full time (68\%), and dedicated at least half of their time to the care of children with phenylalanine hydroxylase (PAH) deficiency (53\%) (Table 1). At the centre level: respondents indicated that the majority of centres (79\%) followed more than 20 patients with PAH deficiency who required regular nutrition services; and cared for both pediatric and adult populations (79\%). Only three centres $(21 \%)$ were reported to have a comprehensive multidisciplinary team that includes a metabolic physician, metabolic dietitian, metabolic nurse, psychologist, social worker and clinical biochemist (Table 1).

\section{Use of published management guidelines of $\mathrm{PAH}$ deficiency (PKU)}

All respondents were aware of published PKU guidelines, referencing the ACMG PKU consensus guideline ${ }^{3}$ and the companion recommendations for the nutrition management of PAH deficiency [2]. Other guidelines that participants mentioned included: "SERC-GMDI PKU Nutrition Management Guidelines" [21], "NIH Consensus Guideline for Management of PKU" [16], "European Guidelines (not specified)", "Publications by Anita Macdonald (not specified)" and "Nutrition Management of Inherited Metabolic Diseases" [22].

\section{Opinions on classification of PAH deficiency severity}

To classify the severity of PAH deficiency 9 of 19 respondents (47\%) reported using only newborn pre-treatment blood phenylalanine (Phe) levels and 8/19 (42\%) used pre-treatment blood Phe levels in combination with either Phe tolerance, $\mathrm{PAH}$ genotype or all three (Fig. 1). One respondent also indicated using blood Phe levels when the patient is catabolic.

We also asked respondents to indicate the specific pre-treatment blood Phe levels that they used to categorize PAH deficiency severity, using typical classification terminology of classical, moderate, and mild PKU, and mild HPA [23] (Table 2). Definitions of these categories varied among respondents.

\section{Blood phenylalanine levels in management and monitoring of phenylalanine hydroxylase deficiency}

The majority of respondents (74\%) reported that they initiate dietary treatment at blood Phe levels of $\geq 360 \mu \mathrm{mol} / \mathrm{L}$ ( $\geq 6 \mathrm{mg} / \mathrm{dL}$ ), although some dietitians support initiating treatment at higher Phe levels (Table 3).
Blood Phe and tyrosine were reported as being monitored by all dietitians, with $95 \%$ also monitoring ferritin (data not shown). More than half also routinely monitor pre-albumin, albumin and vitamins. Forty-seven percent reported routinely monitoring bone density while a small minority reported routine monitoring of essential fatty acids. Among other routinely monitored surrogate biomarkers, homocysteine, carnitine, full amino acid quantification, alkaline phosphatase, complete blood count, trace elements (zinc, selenium, manganese), folate, B12, and 25-hydroxyvitamin D were reported by some respondents (data not shown).

For younger patients, all respondents indicated that the target range for blood Phe levels was $120-360 \mu \mathrm{mol} / \mathrm{dL}$, but opinions varied slightly for patients aged $>10-18$ years old: most dietitians recommended $120-360 \mu \mathrm{mol} / \mathrm{L}$, while some recommended higher target Phe levels, up to $600 \mu \mathrm{mol} / \mathrm{L}$ (Table 3 ). The majority of respondents consider $120 \mu \mathrm{mol} / \mathrm{L}$ to be the lowest acceptable average level for blood Phe, in the long-term (Table 3). A majority would rarely recommend keeping blood Phe levels at the lower end of therapeutic range, by means of a more phe-restricted diet, and specifically would not be comfortable with patients having blood Phe levels lower than $120 \mu \mathrm{mol} / \mathrm{L}$ (Table 3). Nearly half of the respondents (47\%) recommend maintaining blood Phe levels at a higher-end of the therapeutic range for "some patients" (clinical case scenarios were not specified) (Table 3).

\section{Clinic visits and team communication}

As expected, clinic visits were most frequent in infants 0-12 months old, and declined in older age groups (Table 4). After the first year of life, the majority of dietitians indicated seeing their patients less often than once per month, but at least once per year. Similarly, a majority of respondents reported that between-visit communications took place most often with parents of the youngest patients (Table 4). With respect to the means of communication with families between visits, the telephone was used by more dietitians (100\%), than was email (89\%), mail (58\%), fax (32\%), and phone texts (16\%) (data not shown).

All respondents reported discussing individual patients' nutritional management with other members of the health care team. However, only slightly more than half $(11 / 19$, $58 \%$ ) indicated discussing most of their patients on a regular basis, and under a half of respondents $(8 / 19,42 \%)$ reported that these discussions do not occur routinely. Just over one quarter $(5 / 19,26 \%)$ consider multidisciplinary healthcare team communication to be "highly effective", while the majority of respondents $(13 / 19,68 \%)$ report that they find within-team communication to be "somewhat effective", and one dietitian considers it to be not effective (1/19, 6\%). 
Table 1 Sample Characteristics

\begin{tabular}{|c|c|}
\hline Participant Characteristics & Participant n (\%) \\
\hline \multicolumn{2}{|c|}{ Total number of years of practice in nutrition services ( $n=19$ dietitians) } \\
\hline$<1$ year & $2(11 \%)$ \\
\hline $1-2$ years & $1(5 \%)$ \\
\hline $3-5$ years & $2(11 \%)$ \\
\hline $6-10$ years & $5(26 \%)$ \\
\hline $11-15$ years & $4(21 \%)$ \\
\hline$>16$ years & $5(26 \%)$ \\
\hline Working full-time ( $n=19$ dietitians) & $13(68 \%)$ \\
\hline Working part-time & $6(32 \%)$ \\
\hline \multicolumn{2}{|c|}{ Time dedicated to care of PAH deficiency patients ( $n=19$ dietitians) } \\
\hline All of my time & $3(16 \%)$ \\
\hline Less than all of my time but at least half of my time & $7(37 \%)$ \\
\hline Less than half of my time & $9(47 \%)$ \\
\hline Centre Characteristics & Centre $\mathrm{n}(\%)$ \\
\hline \multicolumn{2}{|c|}{ Number of PAH deficiency children actively followed at centre ( $n=14$ centres) } \\
\hline$<10$ & $1(7 \%)$ \\
\hline $10-20$ & $2(14 \%)$ \\
\hline $20-40$ & $8(57 \%)$ \\
\hline$>40$ & $3(22 \%)$ \\
\hline \multicolumn{2}{|c|}{ \# PAH deficiency patients newly diagnosed each year ( $n=14$ centres) } \\
\hline 2 or fewer & $12(86 \%)$ \\
\hline $3-5$ & $2(14 \%)$ \\
\hline \multicolumn{2}{|c|}{ PAH deficiency patient population treated at the centre ( $n=14$ centres) } \\
\hline Pediatric only (0-18 years) & $3(21 \%)$ \\
\hline Pediatric and adult combined & $11(79 \%)$ \\
\hline \multicolumn{2}{|l|}{ 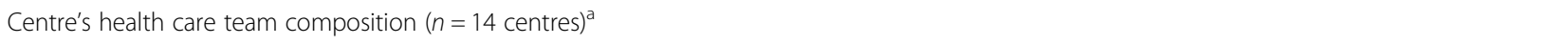 } \\
\hline Dietitian & $14(100 \%)$ \\
\hline Physician & $13(93 \%)$ \\
\hline Metabolic nurse & $9(64 \%)$ \\
\hline Social worker & $7(50 \%)$ \\
\hline Psychologist & $6(43 \%)$ \\
\hline Clinical biochemist & $5(36 \%)$ \\
\hline Genetic counselor & $4(29 \%)$ \\
\hline Nurse-practitioner & $1(7 \%)$ \\
\hline Units used: $\mathrm{mg} / \mathrm{dL}^{\mathrm{b}}$ ( $n=14$ centres) & $2(14 \%)^{b}$ \\
\hline Units used: $\mu \mathrm{mol} / \mathrm{L}$ & $12(86 \%)$ \\
\hline
\end{tabular}

${ }^{a}$ Multiple choice question: the percentages are expected to add up to more than $100 \%$

${ }^{b}$ One of the two centers reporting using $\mathrm{mg} / \mathrm{dL}$, uses $\mathrm{mg} / \mathrm{dL}$ in older patients and umol/L in younger patients

\section{Dietary prescription and assessment}

The most important factors reported to influence the prescription for medical food (formula) were the nutrient composition of formula, patient's age, preferences of the patient or family and availability of the product, reported by $95,89,89$ and $79 \%$ of dietitians, respectively (Table 5). The most commonly prescribed formulas (proportion of dietitians including the formula as within their "top 3") were: Periflex Infant (53\%) and Phenyl free 1 (37\%) for infants < 1 year old; Phenyl free 1 (26\%) and Periflex Junior (26\%) for 1-2 year-olds; Periflex Junior (21\%) and Periflex Junior Plus (21\%) for children aged 3-9 years; and Periflex Advance (21\%) and Phenylade Essential (21\%) for children aged 10-18 years (some of 


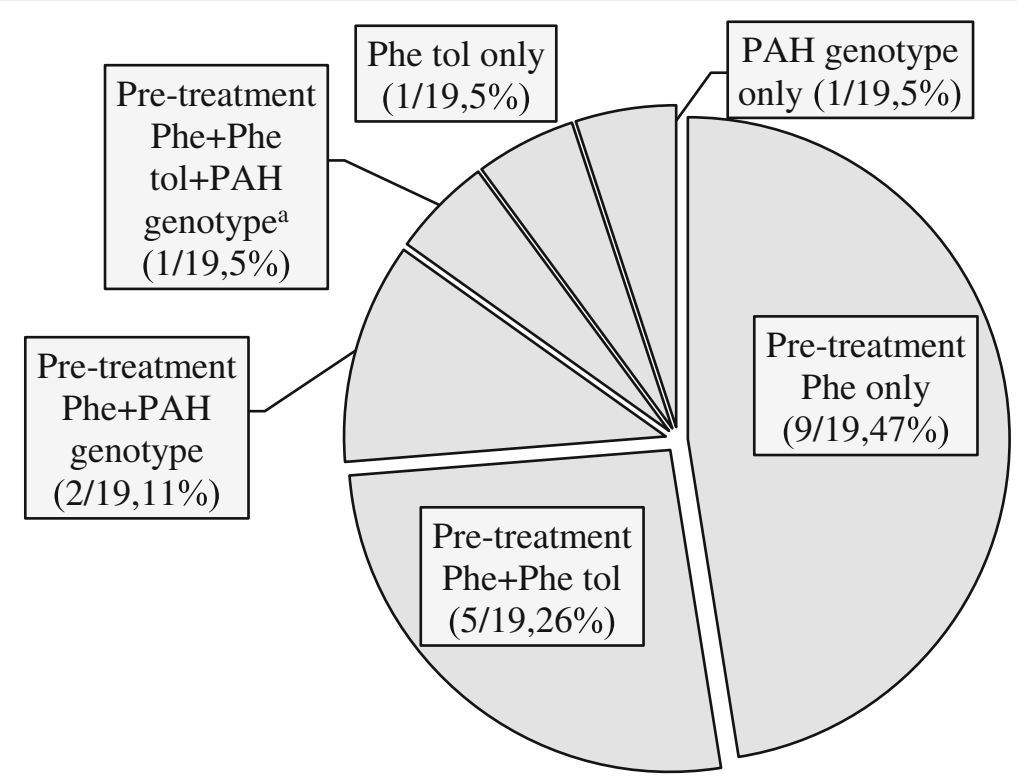

Fig. 1 The respondent also indicated using Phe blood levels when the patient is catabolic

the responses with regard to the different Periflex products reflect periods of transition in their availability). One third of participants (32\%) reported that their choice of formula is limited by the hospital formula contract. Full provincial coverage of the costs of low protein foods was reported by dietitians from 4 centres, while the remainder reported only partial coverage.

The discontinuation of medical formula was reported as "never" considered by $8 / 19$ (42\%) of respondents, while 11/19 (58\%) respondents would consider discontinuing formula in some cases; for example, patients with mild PAH deficiency and those who are good responders to Kuvan (sapropterin dihydrochloride, BH4) (data not shown). With regard to low protein food, good and excellent accessibility was reported by the majority of responders $(17 / 19,89 \%)$. A minority of dietitians (4/ 19, 21\%) reported prescribing large amino-acid supplements (LNAAs) to their pediatric patients.

A majority of dietitians $(17 / 19,89 \%)$ reported 3-day diet records as most frequently used for monitoring nutrition intake adequacy. "Records for the 2 days prior to the bloodwork" and " 2 day diet record" were mentioned by two respondents $(2 / 19,11 \%)$ (data not shown). The most frequently recommended method for self-monitoring of Phenylalanine intake was counting grams of dietary natural protein, reported by $(17 / 19,89 \%)$, followed by regular bloodwork $(14 / 19,74 \%)$, counting milligrams of dietary Phenylalanine (12/19, 63\%), counting Phe exchanges $(9 / 19,47 \%)$ and use of computer applications for PKU $(9 / 19,53 \%)$. Out of those, "counting milligrams of dietary phenylalanine" was the most often recommended method for self-monitoring intake of phenylalanine $(7 / 19,37 \%)$, followed by "counting grams of dietary natural protein" $(4 / 19,21 \%)$. Those who use computer applications, indicated "How much Phe?" as the most frequently reported application (67\%), followed by "Accugo" (25\%) and "Metabolic Diet App" (25\%). Those who reported using Phe exchanges $(9 / 19,47 \%)$, reported calculating 1 exchange as $15 \mathrm{mg}$ of Phenylalanine.

Respondents most frequently reported home sample collection as the method of collecting blood samples for routine monitoring of phenylalanine (95\%), followed by a "local lab or hospital close to patient's house" (68\%) and "metabolic clinic" (63\%) (data not shown).

\section{Monitoring adherence to the medical formula and low protein foods}

To assess patients' adherence to formula intake, dietitians most often reported relying on the verbal report of the parent and/or caregiver (89\%), followed by monitoring blood Phe levels (84\%), monitoring weight and height $(79 \%)$, checking how much formula was released by the dispensing authority (63\%) and analyzing written dietary questionnaire (53\%) (Table 5). As expected, a majority of respondents consider high blood Phe levels to be the most reliable indicator of patients' non-adherence to the diet and/or drug therapy (10/19, $53 \%)$, followed by "not pulling formula from the sources that supply formula" $(5 / 19,26 \%)$, "not doing blood dots on a regular basis" $(3 / 19,16 \%)$ and "not showing up in clinic" (1/19, 5\%) (data not shown).

To improve a patient's adherence to the diet, dietitians employ several strategies, including individualized nutrition counseling (reported by19/19, 100\%), motivational 
Table 2 Reported definitions of PAH deficiency phenotype based on pre-treatment Phe levels ${ }^{a}$

\begin{tabular}{|c|c|}
\hline Reported Phe ranges & $\mathrm{N}$ of respondents/total $\mathrm{N}$ of responded dietitians \\
\hline \multicolumn{2}{|c|}{ How do you define "Mild HPA" based on blood Phe levels in the newborn before treatment? } \\
\hline$<=360 \mu \mathrm{mol} / \mathrm{L}(<=6 \mathrm{mg} / \mathrm{dL})$ & $1 / 9$ \\
\hline$<360 \mu \mathrm{mol} / \mathrm{L}(<6 \mathrm{mg} / \mathrm{dL})$ & $3 / 9$ \\
\hline $120-360 \mu \mathrm{mol} / \mathrm{L}(2-6 \mathrm{mg} / \mathrm{dL})$ & $2 / 9$ \\
\hline $200-360 \mu \mathrm{mol} / \mathrm{L}(3.33-6 \mathrm{mg} / \mathrm{dL})$ & $1 / 9$ \\
\hline $360-600 \mu \mathrm{mol} / \mathrm{L}(6-10 \mathrm{mg} / \mathrm{dL})$ & $1 / 9$ \\
\hline$<600 \mu \mathrm{mol} / \mathrm{L}(<10 \mathrm{mg} / \mathrm{dL})$ & $1 / 9$ \\
\hline \multicolumn{2}{|c|}{ How do you define "Mild PKU" based on blood Phe levels in the newborn before treatment? } \\
\hline $120-360 \mu \mathrm{mol} / \mathrm{L}(2-6 \mathrm{mg} / \mathrm{dL})$ & $1 / 9$ \\
\hline $360-600 \mu \mathrm{mol} / \mathrm{L}(6-10 \mathrm{mg} / \mathrm{dL})$ & $3 / 9$ \\
\hline$<600 \mu \mathrm{mol} / \mathrm{L}(<10 \mathrm{mg} / \mathrm{dL})$ & $1 / 9$ \\
\hline 600-900 $\mu \mathrm{mol} / \mathrm{L}(10-15 \mathrm{mg} / \mathrm{dL})$ & $2 / 9$ \\
\hline $360-1200 \mu \mathrm{mol} / \mathrm{L}(6-20 \mathrm{mg} / \mathrm{dL})$ & $2 / 9$ \\
\hline \multicolumn{2}{|c|}{ How do you define "Moderate PKU" based on blood Phe levels in the newborn before treatment? } \\
\hline$>360 \mu \mathrm{mol} / \mathrm{L}(>6 \mathrm{mg} / \mathrm{dL})$ & $1 / 8$ \\
\hline $600-1000 \mu \mathrm{mol} / \mathrm{L}(10-16.67 \mathrm{mg} / \mathrm{dL})$ & $1 / 8$ \\
\hline 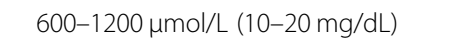 & $3 / 8$ \\
\hline 900-1200 بmol/L (15-20 mg/dL) & $2 / 8$ \\
\hline $1200-1800 \mu \mathrm{mol} / \mathrm{L}(20-30 \mathrm{mg} / \mathrm{dL})$ & $1 / 8$ \\
\hline \multicolumn{2}{|c|}{ How do you define "Classical PKU" based on blood Phe levels in the newborn before treatment?" } \\
\hline$>600 \mu \mathrm{mol} / \mathrm{L}(>10 \mathrm{mg} / \mathrm{dL})$ & $1 / 12$ \\
\hline$\geq 1000 \mu \mathrm{mol} / \mathrm{L}(>16.67 \mathrm{mg} / \mathrm{dL})$ & $1 / 12$ \\
\hline$>1200 \mu \mathrm{mol} / \mathrm{L}(>20 \mathrm{mg} / \mathrm{dL})$ & $7 / 12$ \\
\hline$>1200-1500 \mu \mathrm{mol} / \mathrm{L}(20-25 \mathrm{mg} / \mathrm{dL})$ & $1 / 12$ \\
\hline $1200-2400$ Hmol/L (20-40 mg/dL) & $1 / 12$ \\
\hline$>1800 \mu \mathrm{mol} / \mathrm{L}(>30 \mathrm{mg} / \mathrm{dL})$ & $1 / 12$ \\
\hline
\end{tabular}

${ }^{\mathrm{a}}$ Four respondents indicated that they do not use PKU classification based on pre-treatment Phe levels;

${ }^{\mathrm{b}}$ Two respondents utilize pre-treatment Phe as follows: PKU is diagnosed when pre-treatment Phe is $\geq 1200 \mu \mathrm{mol} / \mathrm{L}$

(classical PKU, included in "classical PKU") and HPA $<1200 \mu \mathrm{mol} / \mathrm{L}$ (not included in the table)

interview techniques and reporting results of blood Phe dots to patients $(14 / 19,74 \%$ and $14 / 19,74 \%$ respectively), and regular reminders to collect/submit blood Phe dots $(10 / 19,53 \%)$. However, regular reminders to collect/submit blood Phe dots were reported to be the least successful of the strategies (Table 5).

Intake of dietary Phe, protein, calories, minerals, and vitamins are routinely monitored for most patients, as reported by the majority of participants (Table 5). All participants reported performing anthropometric measurements at every clinic visit; while both diet analysis and nutrition education were reported as always/often included in routine visits by $90 \%$ of respondents (Table 5).

\section{Discussion}

\section{Reported use of guidelines}

All respondents were aware of the ACMG and GMDI $\mathrm{PAH}$ deficiency consensus guidelines, and almost all respondents reported use of these guidelines. With respect to the GMDI nutrition guidelines, in particular, more detailed information and discussion is provided online at the SERN-GMDI PKU Nutrition Guidelines website including a PKU tool kit with detailed patient diet examples for dietitians [21]. The guidelines are in widespread use but, given the lack of evidence, they often do not recommend a specific course of action related to the most uncertain clinical practice questions (e.g., diet initiation in mild PAH deficiency). These areas of uncertainty were among the most variable aspects of nutritional management reported by the Canadian dietitians in our survey.

\section{Human resources and services in metabolic centres}

Consistent with a previous report [24], our survey identified variation in the organization of care within Canadian metabolic centres. Although the evidence with respect to 
Table 3 Blood Phe levels in treating and monitoring children with PAH deficiency

\begin{tabular}{|c|c|}
\hline & n (\%) \\
\hline \multicolumn{2}{|c|}{ Blood Phe level (consistently elevated) to prompt initiation of a Phe-restricted diet $(n=19)$} \\
\hline$\geq 360 \mu \mathrm{mol} / \mathrm{L}(\geq 6 \mathrm{mg} / \mathrm{dL})$ & $14(74)$ \\
\hline $360-420 \mu \mathrm{mol} / \mathrm{L}(6-7 \mathrm{mg} / \mathrm{dL})$ & $1(5)$ \\
\hline$\geq 420 \mu \mathrm{mol} / \mathrm{L}(\geq 7 \mathrm{mg} / \mathrm{dL})$ & $1(5)$ \\
\hline$\geq 480 \mu \mathrm{mol} / \mathrm{L}(\geq 8 \mathrm{mg} / \mathrm{dL})$ & $2(10)$ \\
\hline$\geq 600 \mu \mathrm{mol} / \mathrm{L}(\geq 10 \mathrm{mg} / \mathrm{dL})$ & $1(5)$ \\
\hline \multicolumn{2}{|l|}{ Optimal target range of blood Phe, by age } \\
\hline \multicolumn{2}{|l|}{$0-12$ months of age $(n=19)$} \\
\hline $120-360 \mu \mathrm{mol} / \mathrm{L}(2-6 \mathrm{mg} / \mathrm{dL})$ & $19(100)$ \\
\hline \multicolumn{2}{|l|}{$>1-2$ years of age $(n=19)$} \\
\hline $120-360 \mu \mathrm{mol} / \mathrm{L}(2-6 \mathrm{mg} / \mathrm{dL})$ & $19(100)$ \\
\hline \multicolumn{2}{|l|}{$>2-10$ years of age $(n=19)$} \\
\hline $120-360 \mu \mathrm{mol} / \mathrm{L}(2-6 \mathrm{mg} / \mathrm{dL})$ & $19(100)$ \\
\hline \multicolumn{2}{|l|}{$>10-18$ years of age $(n=18)$} \\
\hline $120-360 \mu \mathrm{mol} / \mathrm{L}(2-6 \mathrm{mg} / \mathrm{dL})$ & $14(78)$ \\
\hline 120-600 umol/L (2-10 mg/dL) & $2(11)$ \\
\hline $320-600 \mu \mathrm{mol} / \mathrm{L}(5.33-10 \mathrm{mg} / \mathrm{dL})$ & $2(11)$ \\
\hline \multicolumn{2}{|c|}{ Lowest acceptable average level of blood Phe as a long-term treatment goal, by age } \\
\hline \multicolumn{2}{|l|}{$0-12$ months of age $(n=18)$} \\
\hline $100 \mu \mathrm{mol} / \mathrm{L}$ & $1(6)$ \\
\hline $120 \mu \mathrm{mol} / \mathrm{L}$ & $17(94)$ \\
\hline \multicolumn{2}{|l|}{$>1-2$ years of age $(n=17)$} \\
\hline $120 \mu \mathrm{mol} / \mathrm{L}$ & $16(94)$ \\
\hline $150 \mu \mathrm{mol} / \mathrm{L}$ & $1(6)$ \\
\hline \multicolumn{2}{|l|}{$>2-10$ years of age $(n=17)$} \\
\hline $120 \mu \mathrm{mol} / \mathrm{L}$ & $16(94)$ \\
\hline $150 \mu \mathrm{mol} / \mathrm{L}$ & $1(6)$ \\
\hline \multicolumn{2}{|l|}{$>10-18$ years of age $(n=18)$} \\
\hline $100 \mu \mathrm{mol} / \mathrm{L}$ & $1(6)$ \\
\hline $120 \mu \mathrm{mol} / \mathrm{L}$ & $16(89)$ \\
\hline $200 \mu \mathrm{mol} / \mathrm{L}$ & $1(6)$ \\
\hline \multicolumn{2}{|c|}{ Would you be comfortable with a patient's steady Phe level of $<120 \mu \mathrm{mol} / \mathrm{L}(n=19)$} \\
\hline Yes & $6(32)^{a}$ \\
\hline No & $13(68)$ \\
\hline
\end{tabular}

Recommend maintaining higher-end therapeutic range blood Phe and more liberal natural protein intake $(n=19)$

For most/nearly all patients

For some patients

Rarely/never

Recommend maintaining lower-end therapeutic range blood Phe levels and more restricted natural protein intake $(n=19)$

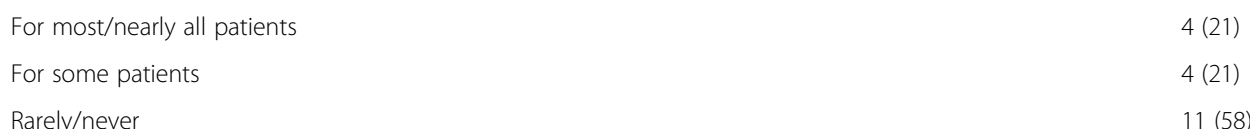

Rarely/never

alf yes, participants were asked to explain - open-ended responses: "If levels were consistent and testing was done weekly, I would be ok it with somewhat lower levels, perhaps as low as 80 ; I would be more comfortable with an older child ( $>2$ years), but this rarely happens; On Kuvan \& hard to increase Phe intake; On restricted diet but growing well; I would be comfortable with $<120 \mathrm{umol} / \mathrm{L}$ in maternal PKU where I was certain formula and calorie intake was optimized and the patient was careful with foods they chose to ensure good nutrition; If patients are experiencing rapid growth (usually in infancy); Only for super responders to Kuvan tolerating DRI total protein from regular protein foods with minimal or no PKU foods" 
Table 4 Clinic visits and communication

\begin{tabular}{|c|c|c|c|c|c|c|}
\hline & $\begin{array}{l}\text { At least } \\
\text { once per week } \\
\mathrm{n}(\%)\end{array}$ & $\begin{array}{l}\text { Less than once } \\
\text { per week but at } \\
\text { least once per month } \\
\mathrm{n}(\%)\end{array}$ & $\begin{array}{l}\text { Less than once } \\
\text { per month but at } \\
\text { least once per year } \\
\mathrm{n}(\%)\end{array}$ & $\begin{array}{l}\text { Less than } \\
\text { once per year } \\
n(\%)\end{array}$ & $\begin{array}{l}\text { Other } \\
\text { n (\%) }\end{array}$ & $\begin{array}{l}\text { GMDI guideline }{ }^{a} \\
\text { n (\%) }\end{array}$ \\
\hline \multicolumn{7}{|c|}{ Reported frequency of clinic visits ${ }^{\mathrm{b}}$} \\
\hline$<1$ year of age & $3(17)$ & $6(33)$ & $8(44)$ & 0 & $1(6)$ & weekly to monthly \\
\hline $1-2$ years of age & 0 & $4(22)$ & $14(78)$ & 0 & 0 & monthly to every 6 months \\
\hline $3-10$ years of age & 0 & $2(11)$ & $16(89)$ & 0 & 0 & \\
\hline $11-18$ years of age & 0 & $2(11)$ & $16(89)$ & 0 & 0 & each $6-12$ months \\
\hline \multicolumn{7}{|c|}{ Reported frequency of communication with patients/family ${ }^{c}$} \\
\hline$<1$ year of age & $15(79)$ & $3(16)$ & 0 & 0 & $1(5)^{d}$ & $1-2$ times per week \\
\hline $1-2$ years of age & $4(22)^{b}$ & $13(72)^{b}$ & 0 & 0 & $1(6)^{\mathrm{b}, \mathrm{e}}$ & once per week to once per month \\
\hline $3-10$ years of age & 0 & $13(69)$ & $5(26)$ & 0 & $1(5)^{\mathrm{e}}$ & \\
\hline $11-18$ years of age & 0 & $9(47)$ & $9(47)$ & 0 & $1(6)^{f}$ & \\
\hline
\end{tabular}

${ }^{\mathrm{a} G M D I}$ recommendations are based on the following age groups: 0-1 year, 1-7 years; 8-18 years

bone missing response $(n=18)$

cvia phone, email, fax, and other means of communication outside of the clinic visit

d"Each month until 3 months old then every 3 months"

e"Based on how frequently family/patients monitor Phe levels. Some [monitor] weekly, some [monitor] every 2 weeks, some [monitor] monthly"

f"Blood work is supposed to be done monthly; if they do it, I will connect with them"

the impact of a coordinated team approach on improved outcomes in the treatment of PAH deficiency is very scarce, one Canadian retrospective study reported that a multidisciplinary centralized approach results in better outcomes in terms of improved adherence to the diet, control of blood Phe, and fewer patients lost to follow up [13]. Both recent American and European guidelines recommend a multidisciplinary coordinated approach to the management of PAH deficiency, where the health care team should include a metabolic physician, dietitian, specialized metabolic laboratory and access to a psychologist and a social worker. Our survey indicated that only 3 out of 14 centres have a metabolic physician, dietitian, biochemist and access to a psychologist; indicating a lack of multidisciplinary care. Only two centres reported having dietitians whose time is fully dedicated to the care of patients with PAH deficiency, but seven centres reported at least a half time dedicated position. These differences likely reflect patient numbers but may also reflect differences in staff time available for patient care. With regard to the communication within the healthcare team, only one quarter of survey respondents regarded this as highly effective, highlighting a need to improve existing communication practices within healthcare teams who provide care to patients with PAH deficiency.

\section{PAH deficiency phenotype classification}

Our survey revealed limited consensus among Canadian dietitians on the definition of the severity of PAH deficiency. To identify the type of PAH deficiency, the majority of dietitians reported use of pre-treatment blood Phe levels alone, or in combination with Phe tolerance and/or genotype. A few dietitians either do not use pre-treatment blood Phe levels for this purpose, or else use them for a modified classification, such as "HPA or classical PKU". Such a lack of clarity most likely created a discrepancy in reporting the use of pre-treatment blood Phe levels, to define the severity of PAH deficiency: Fig. 1 indicated that only two dietitians do not use pre-treatment blood Phe levels for this purpose, but the number increased to four in Table 2, in response to a request to provide a range for each classification of PAH deficiency (PKU); mild HPA, mild PKU, moderate PKU, classical PKU.

Several authors have recommended against each of the indicators as a means of classifying disease severity in the neonatal period $[1,25]$. For example, pre-treatment blood Phe levels typically do not reach a maximum because of prompt diagnosis and treatment onset [1]. In addition, precise Phe tolerance is difficult to determine at the clinic visit setting because of inconsistencies between actual and prescribed dietary Phe intake and other factors, such as a patient's age and/or metabolic state during the period of interest [25]. Finally, PAH genotypes are often difficult to interpret because several mutations are responsible for wide range of clinical phenotypes $[3,26]$. Since none of the above criteria are fully appropriate as a standard for the classification of PAH deficiency, the most recent north American guideline $^{3}$ referred to a previous NIH consensus guideline ${ }^{16}$ that suggested a simplified classification which is based on pre-treatment blood Phe levels [27]. Therefore the respondents to this survey were generally following established practice. 
Table 5 Diet prescription, assessment, and monitoring

Factors considered "very important" in deciding which formula to prescribe

Nutrient composition of formula

Patient's age

Preferences of the patient or family

Availability of the product

Price of the product

Severity of PAH deficiency

Approaches to assessing patient adherence to formula and diet prescription ${ }^{\mathrm{a}}$

By patient's/caregiver's verbal report

Monitoring weight and height

By laboratory tests:

Phenylalanine

Pre-albumin

Tyrosine

B12

Albumin

Checking how much formula was released by the dispensing authority

By analyzing written dietary questionnaires

Technique that is most successful in improving adherence to diet

Individualized PAH deficiency nutrition counseling

Motivational interview techniques

Reporting results of blood dots to patients

Regular reminders for Phe blood dots

0

Nutrients that are routinely monitored for "most" patients, based on diet records ${ }^{a}$

Dietary Phe intake

Protein intake

Calorie intake

Mineral intake (any)

Vitamin intake (any)

Fat intake

Other

Components that are always/often included in routine clinical visit assessments ${ }^{a}$

Anthropometric measurements

Diet education

Dietary analysis

$17(90)$

${ }^{a}$ Multiple choice questions, the percentages are expected to add up to more than $100 \%$

${ }^{\mathrm{b}}$ One missing response $(n=18)$

'Two missing responses $(n=17)$

Determining the severity of PAH deficiency might not seem crucial in the clinical setting where a patient's management is rather dynamic, and directed by the most current blood Phe levels. However, there is a small but feasible risk that overestimation of the degree of severity of PAH deficiency could initially result in over-restriction of the intake of natural protein, until Phe tolerance is empirically determined. Furthermore, if an individual is assumed to have minimal residual PAH activity, and therefore potentially a low chance of responding to sapropterin, he or she may also not be given the opportunity for a $\mathrm{BH} 4$ responsiveness trial $[28,29]$. 
Frequency of clinic visits and provider-family communication Individual adherence to nutrition therapy depends on numerous patient- and healthcare-related factors, and appears to decline with increasing patient age [10, 30]. There is some evidence that gaps in communication between health care providers and patients / families may contribute to nonadherence [11]. As recommended by the 2014 treatment guidelines for PAH deficiency from GMDI, frequency of communication with patients, aged 8-18 years, should occur weekly to monthly [2]. However, nearly half of the survey respondents reported communicating with patients of this age and their families, less frequently than is recommended. Aligned with recommendations though, was the contact with 3-10 year old patients and their families: $68 \%$ of survey respondents reported their frequency of communication to be 1-3 times per month. Decreased frequency of contact with older children is likely due to decreased frequency of home blood Phe monitoring, especially as patients learn to become independent in managing their daily diets and home blood draws. However, other factors may also offer an explanation for the failure to meet recommendations: staff shortages in the metabolic clinic and subsequent time limitations; disappointment with non-adherent patients; other social, psychological, economical and human resource related barriers [31-33]. The decline in the frequency of communication that we observed might contribute to non-adherence with treatment in adolescents. The evidence suggests that continuing communication and education throughout childhood, and perhaps reinforcement of the frequency and quality of communication might promote better adherence and subsequently may improve long-term outcomes in older children and adults [11].

We did not ask participants about the frequency of blood Phe measurements. However, we believe that there is a relatively close correspondence between the frequency of communication of dietitians with patients/ families and the frequency of blood Phe measurements, since typically each blood Phe result triggers communication with the patient / family.

\section{Treatment initiation}

There is a good evidence and expert agreement that treatment for $\mathrm{PAH}$ deficiency should be initiated at $\geq 600 \mu \mathrm{mol} / \mathrm{L} \quad(10 \mathrm{mg} / \mathrm{dL}) \quad[3,34]$. However there is lack of conclusive evidence on the balance between "added benefit" and "no harm" of treatment initiation at $\geq 360-600 \mu \mathrm{mol} / \mathrm{L} \quad(6-10 \mathrm{mg} / \mathrm{dL})$. This uncertainty translates into provisional practice recommendations [3, 12, 34]. Not surprisingly, our survey found that the majority of dietitians set the threshold for initiation of therapy at $\geq 360 \mu \mathrm{mol} / \mathrm{L}(\geq 6 \mathrm{mg} / \mathrm{dL})$, and several others at higher blood Phe levels. In alignment with the evidence and published guidelines, all would begin dietary Phe restriction when the blood Phe level is $\geq 600 \mu \mathrm{mol} / \mathrm{L}(10 \mathrm{mg} / \mathrm{dL})$.

\section{Prescribing LNAA}

Since this was a survey of pediatric practice, less than a quarter of respondents reported prescribing supplements of large neutral amino acids (LNAA). Animal and human studies show that Phe competes with LNAAs for the protein carrier through the intestinal wall and the blood brain barrier. Thus the lack of LNAAs, in of itself, might promote higher Phe levels in the central nervous system $[35,36]$. There is mainly positive but limited evidence on the benefit of LNAA supplementation in treatment of PAH deficiency. Therefore, as the LNAA content in PKU medical foods (formulas) can vary, more research especially on the safety and long-term outcomes of treatment with LNAAs is clearly needed [37, 38]. As mentioned in the ACMG guidelines, current use of LNAA is limited to adolescents and adults, with avoidance in pregnancy. A European panel of PKU experts gave no statement on the use of LNAAs [3, 14].

\section{Limitations}

Our survey focused on PAH deficiency in the pediatric population and thus we cannot comment on the transition to adult care, nor to adult nutrition management.

While our response rate was reasonable (59\%) for a survey of health care providers and represented almost all Canadian metabolic centers (14 out of 16) and provinces and territories, with the exception of Nunavut and Newfoundland and Labrador, the views of participants may not represent those of all metabolic dietitians in Canada; for example, the individuals who did not respond to the survey may be less aware of, or adherent to, current guidelines. Another major limitation of this survey was that we did not address how much Phe, tyrosine and protein (medical foods/formulas and natural protein), in relation to age, was prescribed in each center; nor what proportion of these prescriptions were aligned with recommendations. We believed that such detailed nutritional data should be derived from clinical reviews (e.g., from chart reviews), which was outside the scope of this publication.

\section{Conclusion}

We found that Canadian metabolic dietitians generally follow published guidelines in their nutritional management of pediatric PAH deficiency. Dietitians responded with some variation, both across and within centres. The most striking differences were in approaches to defining PAH deficiency phenotype, treatment targets for blood Phe levels, frequency of clinic-patient communication with older children, and organization of care in 
metabolic centres. More research is needed to generate better evidence, with which to address the current gaps in knowledge in relation to treatment of PAH deficiency, variation in laboratory monitoring and clinic visit frequency; with subsequent translation into practice.

\author{
Abbreviations \\ ACMG: American College of Medical Genetics and Genomics; \\ CIMDRN: Canadian Inherited Metabolic Diseases Research Network: \\ GMDI: Genetic Metabolic Dietitians International; \\ HPA: Hyperphenylalaninemia; IMD: Inherited metabolic diseases; \\ $\mathrm{NIH}$ : National Institutes of Health; OMIM: Online mendelian inheritance in \\ man; PAH: Phenylalanine hydroxylase; Phe: Phenylalanine; \\ PKU: Phenylketonuria; REDCap: Research electronic data capture; \\ SERN: Southeast regional genetics network
}

\section{Acknowledgements}

We would like to thank Canadian Metabolic Dietitians for their support of this project.

\section{Funding}

This work was supported by a Canadian Institutes of Health Research (CIHR) Emerging Team grant and the University of British Columbia.

\section{Availability of data and materials}

The datasets analyzed during the current study is available from the corresponding author on reasonable request.

\section{Authors' contributions}

NY coordinated and carried the survey project, including the design of the survey, submission to the Research Ethics Board, data analysis, and manuscript writing. BP supervised survey development and manuscript writing $S S, K U, V A, S R$, EL, AG, BB, MC substantially contributed to the concept and design of the study, revision of the survey questionnaire and critical review of the manuscript. BP and VA also provided the final proofread of the manuscript. JP and PC contributed to the concept and design of the study, and critical review of the manuscript. AP contributed to the design of the study and data acquisition. All authors read and approved the final manuscript.

\section{Ethics approval and consent to participate}

The survey study protocol was submitted to Research Ethics Board of the University of British Columbia and received initial REB approval in August 8, 2015 (H15-01291).

\section{Consent for publication}

Not applicable.

\section{Competing interests}

Dr. Stockler received research funding for clinical trials related to PAH deficiency (PKU015, PKU 016, BioMarin). The other authors declare no competing interests.

\section{Publisher's Note}

Springer Nature remains neutral with regard to jurisdictional claims in published maps and institutional affiliations.

\footnotetext{
Author details

'University of British Columbia, Vancouver, British Columbia, Canada. ${ }^{2}$ University of Ottawa, Ottawa, Ontario, Canada. 'British Columbia Children's Hospital, Vancouver, British Columbia, Canada. ${ }^{4}$ Children's Hospital of Eastern Ontario, Ottawa, Ontario, Canada. ${ }^{5}$ Children's Hospital of Western Ontario, London, Ontario, Canada. ${ }^{6}$ The Hospital for Sick Children (SickKids), Toronto, Ontario, Canada. ${ }^{7}$ IWK Health Centre Medical Genetics, Halifax, Nova Scotia, Canada. ${ }^{8}$ McMaster Children's hospital, Hamilton, Ontario, Canada.
}

Received: 9 July 2018 Accepted: 11 December 2018

Published online: 08 January 2019

\section{References}

1. Blau N, van Spronsen FJ, Levy HL. Phenylketonuria. Lancet. 2010;376:1417-27.

2. Singh RH, Rohr F, Frazier $D$, et al. Recommendations for the nutrition management of phenylalanine hydroxylase deficiency. Genet Med. 2014; 16(2):121-31.

3. Vockley J, Andersson HC, Antshel KM, Braverman NE, Burton BK, Frazier DM, Mitchell J, Smith WE, Thompson BH, Berny SA. Phenylalanine hydroxylase deficiency: diagnosis and management guideline. Genet Med. 2014;16:188-200.

4. van Wegberg AMJ, MacDonald A, Ahring K, Bélanger-Quintana A, Blau N, Bosch AM, Burlina A, Campistol J, Feillet F, Giżewska M, Huijbregts SC, Kearney S, Leuzzi V, Maillot F, Muntau AC, van Rijn M, Trefz F, Walter JH, van Spronsen FJ. The complete European guidelines on phenylketonuria: diagnosis and treatment. Orphanet J Rare Dis. 2017;12:162.

5. Waisbren SE, Noel K, Fahrbach K, et al. Phenylalanine blood levels and clinical outcomes in phenylketonuria: a systematic literature review and meta-analysis. Mol Genet Metab. 2007;92:63-70.

6. Smith I, Knowles J. Behaviour in early treated phenylketonuria: a systematic review J. Eur J Pediatr. 2000;159(Suppl 2):S89.

7. Enns GM, Koch R, Brumm V, Blakely E, Suter R, Jurecki E. Suboptimal outcomes in patients with PKU treated early with diet alone: revisiting the evidence. Mol Genet Metab. 2010;101:99-109.

8. Landolt MA, Nuoffer JM, Steinmann B, Superti-Furga A. Quality of life and psychologic adjustment in children and adolescents with early treated phenylketonuria can be normal. J Pediatr. 2002;140:516-21.

9. Diamond A. Monographs of the Society for Research in Child Development: Prefrontal cortex cognitive deficits in children treated early and continuously for PKU. Monogr Soc Res Child Dev. 1997;62(4):i-v 1-208.

10. Jurecki ER, Cederbaum S, Kopesky J, Perry K, Rohr F, Sanchez-Valle A, Viau KS, Sheinin MY, Cohen-Pfeffer JL. Adherence to clinic recommendations among patients with phenylketonuria in the United States. Mol Genet Metab. 2017;120(3):190-7.

11. MacDonald A, Gokmen-Ozel H, van Rijn M, Burgard P. The reality of dietary compliance in the management of phenylketonuria. J Inherit Metab Dis. 2010;33(6):665-70

12. Weglage J, Pietsch M, Feldmann R, et al. Normal clinical outcome in untreated subjects with mild hyperphenylalaninemia. Pediatr Res. 2001;49:532-6.

13. Camfield CS, Joseph M, Hurley T, Campbell K, Sanderson S, Camfield PR. Optimal management of phenylketonuria: a centralized expert team is more successful than a decentralized model of care. J Pediatr. 2004;145:53-7.

14. van Spronsen FJ, van Wegberg AM, Ahring K, Bélanger-Quintana A, Blau N, Bosch AM, Burlina A, Campistol J, Feillet F, Giżewska M, Huijbregts SC, Kearney S, Leuzzi V, Maillot F, Muntau AC, Trefz FK, van Rijn M, Walter JH, MacDonald A. Key European guidelines for the diagnosis and management of patients with phenylketonuria. Lancet Diabetes Endocrinol. 2017;5(9):743-56.

15. European Society for Phenylketonuria and Allied Disorders: PKU: Closing the Gaps in Care. An ESPKU benchmark report on the management of phenylketonuria within EU healthcare economies. Available at: http://www. espku.org/wp-content/uploads/2015/06/PKU_report_FINAL_V2_nomarks.pdf. Accessed 1 Feb 2018.

16. National Institutes of Health Consensus Development Panel, National Institutes of Health Consensus Development Conference Statement. Phenylketonuria (PKU): Screening and Management, October 16-18, 2000. Pediatrics. 2001;108:972-82.

17. Lindegren ML, Krishnaswami S, Fonnesbeck C, et al. Adjuvant Treatment for Phenylketonuria (PKU). Rockville: Agency for Healthcare Research and Quality (US); 2012. (Comparative Effectiveness Reviews, No. 56.) Available at: https://www.ncbi.nlm.nih.gov/books/NBK91350/. Accessed 12 Mar 2018

18. Singh RH, Rohr F, Splett PL. Bridging evidence and consensus methodology for inherited metabolic disorders: creating nutrition guidelines. J Eval Clin Pract. 2011;19:584-90.

19. Dillman DA. Mail and internet surveys. The tailored design method. 2nd ed. New York: Wiley, Inc; 2007

20. van Geest JB, Johnson TP, Welc VL. Methodologies for improving response rates in surveys of physicians: a systematic review. Eval Health Prof. 2007;30: $303-21$.

21. SERC-GMDI PKU Nutritional Guidelines. Available at: https:// southeastgenetics.org/ngp/guidelines.php/90/ PKU\%20Nutrition\%20Guidelines/Nersion\%201.12. Accessed 28 Mar 2018. 
22. Bernstein LE, Rohr F, Helm JR (eds). Nutrition Management of Inherited Metabolic Diseases, Springer International Publishing Switzerland; 2015.

23. Güttler F. Acta pædiatrica Scandinavica. Supplement:

Hyperphenylalaninemia: diagnosis and classification of the various types of phenylalanine hydroxylase deficiency in childhood. Almquist Wiksell. 1980; 280:1.

24. Lamoureux MF, Tingley K, Kronick JB, Potter BK, Chan AK, Coyle D, Dodds L, Dyack S, Feigenbaum A, Geraghty M, Gillis J, Rockman-Greenberg C, Khan A, Little J, MacKenzie J, Maranda B, Mhanni A, Mitchell JJ, Mitchell G, Laberge AM, Potter M, Prasad C, Siriwardena K, Speechley KN, Stockler S, Trakadis Y, Turner L, Van Karnebeek C, Wilson K, Chakraborty P. Canadian Inherited Metabolic Diseases Research Network. Metabolic Clinic Atlas: Organization of Care for Children with Inherited Metabolic Disease in Canada. JIMD Rep. 2015;21:15-22.

25. van Spronsen F, van Rijn M, Dorgelo B, Hoeksma M, Bosch AM, Mulder MF, de Klerk JBC, de Koning T, Estela Rubio-Gozalbo M, de Vries M, Verkerk PH. Phenylalanine tolerance can already reliably be assessed at the age of 2 years in patients with PKU. J Inherit Metab Dis. 2009;32:27.

26. Quirk ME, Dobrowolski SF, Nelson BE, Coffee B, Singh RH. Utility of phenylalanine hydroxylase genotype for tetrahydrobiopterin responsiveness classification in patients with phenylketonuria. Mol Genet Metab. 2012; 107(0):31-6.

27. Blau N, Hennermann JB, Langenbeck U, Lichter-Konecki U. Diagnosis, classification, and genetics of phenylketonuria and tetrahydrobiopterin (BH4) deficiencies. Mol Genet Metab. 2011;104(Suppl):S2-9.

28. Fiege B, Blau N. Assessment of tetrahydrobiopterin (BH4)-responsiveness in phenylketonuria. J Pediatr. 2007;150:627-30.

29. Burton BK, Grange DK, Milanowski A, Vockley G, Feillet F, Crombez EA, Abadie V, Harding CO, Cederbaum S, Dobbelaere D, Smith A, Dorenbaum A. The response of patients with phenylketonuria and elevated serum phenylalanine to treatment with oral sapropterin dihydrochloride (6Rtetrahydrobiopterin): a phase II, multicenter, open-label, screening study. J Inherit Metab Dis. 2007;30:700-7.

30. Hartnett C, Salvarinova-Zivkovic R, Yap-Todos E, Cheng B, Giezen A, Horvath G, Lillquist Y, Vallance H, Stockler-Ipsiroglu S. Long-term outcomes of blood phenylalanine concentrations in children with classical phenylketonuria. Mol Genet Metab. 2013;108(4):255-8.

31. MacDonald A, Davies P, Daly A, Hopkins V, Hall SK, Asplin D, et al. Does maternal knowledge and parent education affect blood phenylalanine control in phenylketonuria? J Hum Nutr Diet. 2008;21:351-8.

32. Walter JH, White FJ, Hall SK, MacDonald A, Rylance G, Boneh A, et al. How practical are recommendations for dietary control in phenylketonuria? Lancet. 2002;360:55-8.

33. Sharman R, Mulgrew K, Katsikitis M. Qualitative Analysis of Factors Affecting Adherence to the Phenylketonuria Diet in Adolescents. Clin Nurse Spec. 2013;27(4):205-10.

34. van Spronsen FJ. Mild hyperphenylalaninemia: to treat or not to treat. J Inherit Metab Dis. 2011;34(3):651-6.

35. Surtees R, Blau N. The neurochemistry of phenylketonuria. Eur J Pediatr. 2000;10:159 Suppl 2.

36. Blau N, Shen N, Carducci C. Molecular genetics and diagnosis of phenylketonuria: state of the art. Expert Rev Mol Diagn. 2014;14(6):655-71.

37. van Spronsen FJ, De Groot MJ, Hoeksma M, Reijngoud DJ, Van Rijn M. Large neutral amino acids in the treatment of PKU: from theory to practice. J Inherit Metab Dis. 2010;33:671-6.

38. Matalon R, Michals-Matalon K, Bhatia G, Burlina AB, Burlina AP, Braga C, Fiori L, Giovannini M, Grechanina E, Novikov P, Grady J, Tyring SK, Guttler F. Double blind placebo control trial of large neutral amino acids in treatment of PKU: effect on blood phenylalanine. J Inherit Metab Dis. 2007;30(2):153-8.

Ready to submit your research? Choose BMC and benefit from:

- fast, convenient online submission

- thorough peer review by experienced researchers in your field

- rapid publication on acceptance

- support for research data, including large and complex data types

- gold Open Access which fosters wider collaboration and increased citations

- maximum visibility for your research: over $100 \mathrm{M}$ website views per year

At BMC, research is always in progress.

Learn more biomedcentral.com/submissions 